\title{
Disability Leave
}

National Cancer Institute

\section{Source}

National Cancer Institute. Disability Leave. NCI Thesaurus. Code C148252.

A leave of absence granted because of physical or mental disability. 